九州大学学術情報リポジトリ

Kyushu University Institutional Repository

\title{
Evaporation from Irrigation Canals in the Middle Reaches of the Heihe River in the Northwest of China : A Preliminary Study
}

Wang, We izhen

Cold and Arid Regions Environmental and Engineering Institute, CAS

Liu, Suhua

Cold and Arid Regions Environmental and Engineering Institute, CAS

Kobayashi, Tetsuo

Cold and Arid Regions Environmental and Engineering Institute, CAS

Kitano, Masaharu

Laboratory of Agricultural Meteorology, Division of Bioproduction Environmental Sciences, Department of Agro-environmental Sciences, Faculty of Agriculture, Kyushu University

https://doi.org/10.5109/27369

出版情報: 九州大学大学院農学研究院紀要. 58 (2)，pp.371-376，2013-09. Faculty of Agriculture， Kyushu University

バージョン :

権利関係 : 


\title{
Evaporation from Irrigation Canals in the Middle Reaches of the Heihe River in the Northwest of China - A Preliminary Study-
}

\author{
Weizhen WANG ${ }^{1}$, Suhua LIU ${ }^{1}$, Tetsuo KOBAYASHI ${ }^{1}$ and Masaharu KITANO*
}

Laboratory of Agricultural Meteorology, Division of Bioproduction Environmental Sciences, Department of Agro-environmental Sciences, Faculty of Agriculture, Kyushu University, Fukuoka 812-8581, Japan

(Received April 25, 2013 and accepted May 9, 2013)

\begin{abstract}
In the northwest of China, the leakage and evaporation from irrigation canals is an important issue from the stand point of efficient use of water resources, because long canals have been constructed for farmland irrigation. In order to estimate the evaporation from irrigation canals a preliminary study was conducted in the middle reaches of the Heihe River during the summer months based on the heat balance method. The rate of evaporation from irrigation canals depends on the temperature difference between canal water and air, the air humidity, and the wind speed. The present observations showed that the seasonal variations of the temperature difference and the wind speed were not large in the observation period, and the seasonal variation of air humidity had a large influence on the evaporation rate. Since the Heihe River rises from the Qilian Mountains and the river water is melt-water, the water temperature is rather low compared to the air temperature. As a result, daily evaporation depth was often almost zero or negative. The results of this study were obtained by applying the relationship between the heat transfer coefficients and the surface wind speed empirically derived by Mihara et al. (1959b), so the results are only approximate. Hence, these results should be verified against observational evidence before a final conclusion can be drawn.
\end{abstract}

Key words: evaporation, heat balance method, Heihe River, irrigation canal

\section{INTRODUCTION}

If irrigation canals are unpaved ditches, we can conceive that a considerable amount of irrigation water is lost due to the leakage into the ground through the bottom and side wall of canals during its transport from a sluice gate to fields (Huang et al., 2010).

In China, irrigation canals are classified into five groups; that is, gan qu (main canal), zhi qu (branch canal), dou qu (lateral canal), nong qu (field canal), and mao qu (field ditch). In the present study area, the middle reaches of the Heihe River (Fig. 1), the main and branch canals extending for $4,700 \mathrm{~km}$ have been paved. The total length of the lateral and field canals is $14,000 \mathrm{~km}$, and the lateral canals have almost been paved and $30 \%$ of the field canals have been paved. In other words, water is leaking mainly from field canals and field ditches; that is, the leakage occurs mostly in or near irrigated fields, not in transport from an intake upriver to the irrigated fields.

In arid regions, however, the evaporation from the water surface of irrigation canals should be responsible for the loss. Since it is difficult to measure the evaporation from a limited land surface with a surface condition different from the surrounding area, and also to apply the evaporation pan or the lysimeter to running water surfaces, few researches and investigations into this subject have been carried out.

In the late 1940 s and early 1950 s, the north or highland regions of Japan suffered the damage caused by cold

${ }^{1}$ Cold and Arid Regions Environmental and Engineering Institute, CAS, China

* Corresponding author (E-mail: kitano@bpes.kyushu-u.ac.jp)

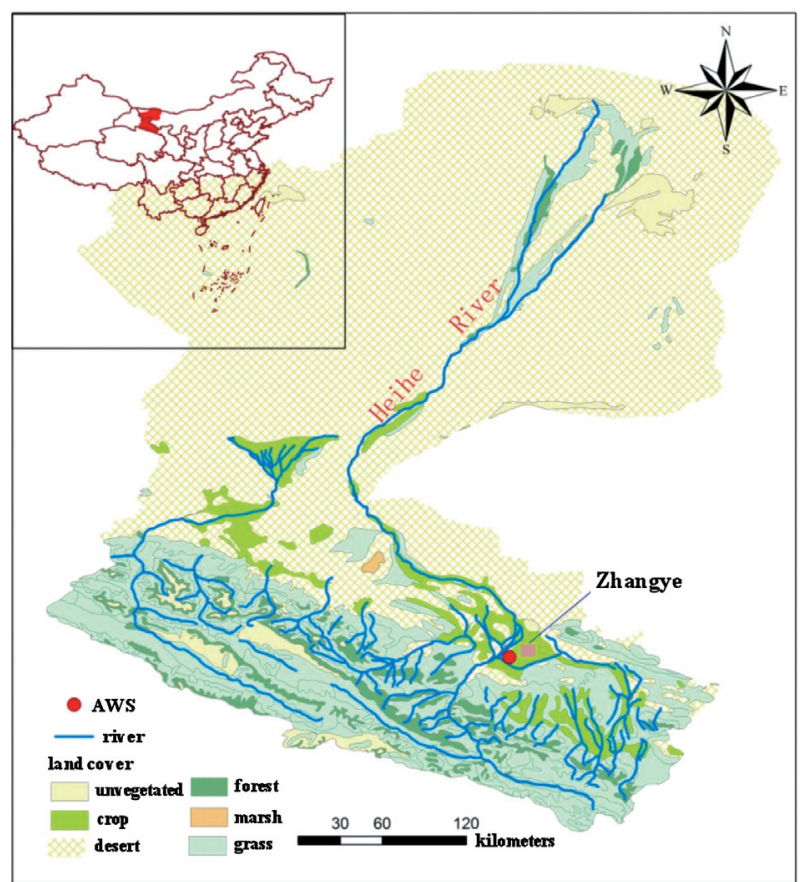

Fig. 1. Map of the Heihe River basin in the northwest of China.

weather to the paddy rice. The cold irrigation water arrests the paddy rice to grow and decreases its yield. Therefore, many water-warming ponds and canals were constructed. Mihara et al. (1959a) conducted a study of the heat balance of the water warming ponds (1959a). As a sequel to the study they also studied the heat balance of the water warming canals (1959b) in order to determine the rate of heat transfer between the running water surface and the surface air layer, and to make clear the characteristics of heat balance of the canal and 
the change in temperature of the flowing water in the canal. As a result, they found that the water in the canals was warmed more by sensible and latent heat fluxes than by net radiation; that is, they estimated that not only sensible heat flux but also latent heat flux were negative or downward over the water surface in the canal. They also derived empirically the sensible and latent heat transfer coefficients as functions of the wind velocity.

This paper describes the method for estimating the latent heat flux over the water surface of a canal based on the heat balance analysis of the water flowing in the canal; in addition, the results of a preliminary study of the evaporation from irrigation canals in the middle reaches of the Heihe River in the northwest of China (Fig. 1) by applying the sensible and latent heat transfer coefficients as functions of the surface wind velocity obtained by Mihara et al. (1959b), so the results are only approximate.

\section{HEAT BALANCE METHOD}

Firstly, the heat balance method for estimating the evaporation from the water surface of an irrigation canal is outlined as an introduction to our application.

Figure 2 shows the schematic of a part of irrigation water flowing in a canal with rectangular cross section, being $B(\mathrm{~m})$ in width, $L(\mathrm{~m})$ in length, and $D_{w}(\mathrm{~m})$ in water depth. This is the water body element of which the heat balance is examined. It is assumed that the flow speed $V\left(\mathrm{~m} \mathrm{~s}^{-1}\right)$ or discharge $\left(\mathrm{m}^{3} \mathrm{~s}^{-1}\right)$ is invariable with the distance along the flow direction ( $x$-direction), or water leakage and evaporation are negligible, and the temperature $T_{w}(\mathrm{~K})$ of the water flowing into the volume element at $x=0$ is $T_{w, \text { in }}$, and that of the water flowing out of the element at $x=L$ is $T_{w, \text { out }}$. The net radiation, sensible heat flux, latent heat flux, and ground heat flux, are expressed by $R_{N}, H, \lambda E$, and $G$, given in $\mathrm{W} \mathrm{m}^{-2}$, respectively. Here, the direction of an arrow in Fig. 2 points the positive direction of each term.

The energy balance of the water body element during a period of time, $\Delta t(\mathrm{~s})$, is described as follows, if the heat flux through the side wall is negligible:

$$
\begin{aligned}
c \rho & V\left(T_{w, \text { in }}-T_{w, \text { out }}\right) B D_{w} \Delta t+R_{N} L B \Delta t \\
\quad & c \rho \frac{\partial T_{W}}{\partial t} L B D_{w} \Delta t+(H+\lambda E+G) L B \Delta t
\end{aligned}
$$

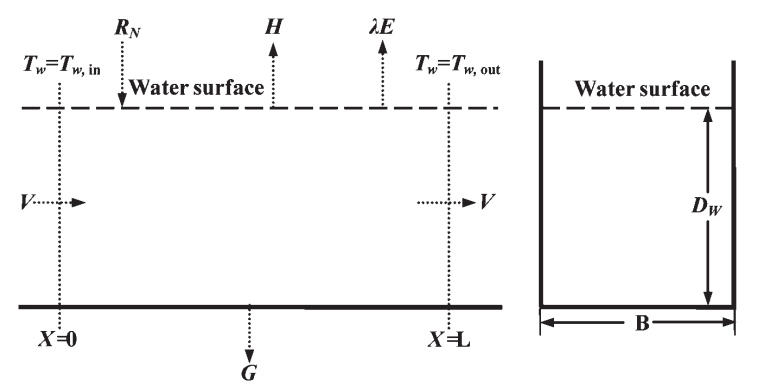

Fig. 2. Heat balance of water flowing in an irrigation canal. A side view (left) and a cross-sectional view (right). See text for explanation. where $c \rho$ : heat capacity of liquid water $\left(\mathrm{J} \mathrm{m}^{-3} \mathrm{~K}^{-1}\right)$. This equation can be rewritten as:

$$
\begin{aligned}
c \rho & Q\left(T_{w, \text { in }}-T_{w, \text { out }}\right)+\left[R_{N}\right] \\
& =c \rho \frac{\partial T_{W}}{\partial t} L B D_{w} \Delta t+[H]+[\lambda E]+[G]
\end{aligned}
$$

where $\mathrm{Q} \equiv V B D_{w} \Delta t\left(\mathrm{~m}^{3}\right)$ is the flow, and the flux terms $[X] \equiv X L B \Delta t(J)$. Since the water temperature is empirically known to change linearly with time, if the mean water temperature of the volume element is expressed as $T_{w, m}=\frac{1}{2}\left(T_{w, \text { in }}-T_{w, \text { out }}\right)$, the first term on the right side of Eq.(2) is given as follows.

$$
c \rho \frac{\partial T_{W}}{\partial t} L B D_{w} \Delta t=c \rho L B D_{w}\left\{T_{w, m}(t+\Delta t)-T_{w, m}(t)\right\}
$$

The net radiation $\left[R_{N}\right]$ is measured or calculated as follows.

$$
\begin{aligned}
{\left[R_{N}\right] } & =\left[R_{S \downarrow}\right]-\left[R_{S \uparrow}\right]+\left[R_{L \downarrow}\right]-\left[R_{L \uparrow}\right] \\
& =\left[R_{S \downarrow}\right](1-\alpha)+\varepsilon\left\{\left[R_{L \downarrow}\right]-\left[\sigma T_{w, m}{ }^{4}\right]\right\}
\end{aligned}
$$

where $R_{S \downarrow}$ : short wave downward radiation, $R_{L \downarrow}$ : long wave downward radiation, $R_{S \uparrow}$ : short wave upward radiation, $R_{L \uparrow}$ : long wave upward radiation, $\alpha$ : albedo of the water surface, $\varepsilon$ : emissivity of the water surface, $\sigma$ : StefanBoltzmann constant.

The ground heat flux $[G]$ is measured directly with heat flux plates or calculated based on the ground temperature measurements. Let us assume that the soil temperature below the bottom of a canal is expressed as (Kobayashi, 2012):

$$
\theta(z, t)=\theta_{m}(z)+A(0) \exp (-z / D) \sin \left(\omega t+\phi_{0}-z / D\right)
$$

where $z$ : depth below the bottom (positive downward) (m), $D$ : damping depth $\left.(=2 \alpha / \omega)^{1 / 2}\right)(\mathrm{m}), \alpha$ : thermal diffusivity $\left(\mathrm{m}^{2} \mathrm{~s}^{-1}\right), \omega$ : angular frequency. Then we get

$$
\begin{aligned}
G & =-k\left(\frac{\partial \theta}{\partial z}\right)_{z=0}=-k \frac{\partial \theta_{m}(z)}{\partial z} \\
& +A(0)\left(k \rho_{S} C_{S} \omega\right) 1 / 2 \sin \left(\omega t+\phi_{0}+\frac{\pi}{4}\right)
\end{aligned}
$$

where $k$ : heat conductivity $\left(\mathrm{W} \mathrm{m}^{-1} \mathrm{~K}^{-1}\right), \rho_{S} C_{S}$ : heat capacity of the soil $\left(\mathrm{J} \mathrm{m}^{-3} \mathrm{~K}^{-1}\right)$. If $\Delta t$ is one day, we can approximately get $[G]=\left[-k \frac{\partial \theta_{m}(z)}{\partial z}\right]$. The heat flux through the side wall is approximately estimated to be $\delta \equiv 2 D w / B$ times as large as that through the bottom.

The sensible and latent heat fluxes, $[H]$ and $[\lambda E]$ are obtained from the residual term of the heat balance equation:

$$
\begin{aligned}
{[\text { Res }] } & \equiv[H]+[\lambda E]=c \rho Q\left(T_{w, \text { in }}-T_{w, o u t}\right) \\
& +\left[R_{N}\right]-c \rho L B D_{w} \frac{\partial T_{w}}{\partial t} \Delta t-[G]
\end{aligned}
$$


Here the residual term $[R e s] \equiv[H]+[\lambda E]$ is divided into $[H]$ and $[\lambda E]$ in the ratio of $\bar{\beta}$ to one, where $\bar{\beta}$ is the time averaged Bowen ratio for the period $\Delta t$; that is,

$$
\bar{\beta} \equiv \frac{[H]}{[\lambda E]} \approx \frac{1}{n} \sum_{i=1}^{i=n} \gamma\left(\frac{T_{a}-T_{w}}{e_{a}-e_{s}\left(T_{w}\right)}\right)_{i}
$$

Here, $n$ : number of measurements during $\Delta t, \gamma=\frac{P C_{P}}{0.622 \lambda}$ : psychrometric constant $\left(\mathrm{hPa} \mathrm{K}^{-1}\right), e_{s}(T)$ : saturated vapor pressure at temperature $T(\mathrm{hPa})$, and other symbols have their usual meaning. Then we obtain

$$
\begin{aligned}
& {[H]=\frac{\bar{\beta}}{1+\bar{\beta}}[\text { Res }]} \\
& {[\lambda E]=\frac{1}{1+\bar{\beta}}[\text { Res }]}
\end{aligned}
$$

\section{MATERIALS AND METHODS}

\section{Study area}

The study area is located in the Zhangye oasis (1,400-1,600 m a.s.l.), Gansu, China, which is the core part of the middle reaches of the Heihe River (Fig. 1). The annual mean temperature is $7.0 \mathrm{C}$ and the annual mean precipitation is $124.9 \mathrm{~mm}$. The potential evaporation is much larger than the precipitation, which is more than 2,000 mm. Main crops cultivated in this area are corn, wheat, and others, such as vegetables and fruits. Almost all the farmland in this area is irrigated with the water conducted from the Heihe River.

\section{Preliminary observations}

Meteorological measurements used in this study were made at AWS No.5 and No.11 (1500 m a.s.l.) of the

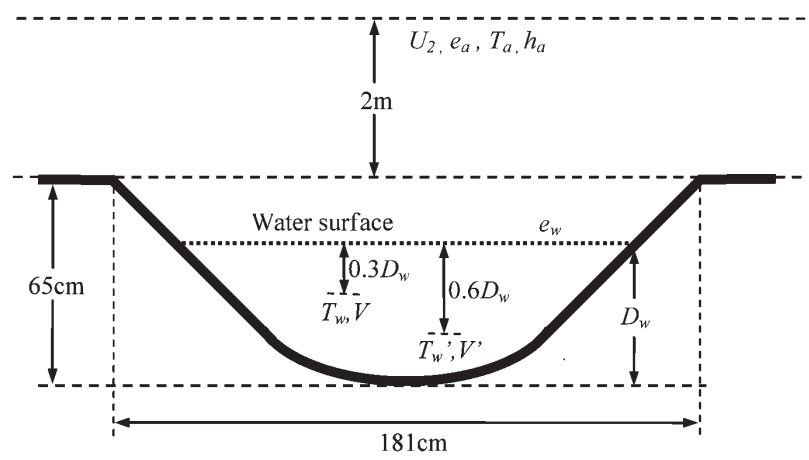

Fig. 3. The cross section of the canal and the measurements points of water flow speed and temperature.
HiWATER project (Li et al., 2012). Table 1 shows the general description of a part of the instruments installed at the AWSs.

When irrigations were practiced, the observation of the water temperature and flow speed was conducted at a dou qu (lateral canal) site, which was situated about $500 \mathrm{~m}$ from the AWSs. In 2012, the preliminary observation was carried out three times during the periods of 22-24 June, 21-24 July, and 13-15 August. Fig. 3 shows the cross section of the canal and the measurement points of water flow speed and temperature.

\section{Fundamental equations}

The sensible heat flux from the water surface is expressed as:

$$
H=\frac{1}{r_{a h}} \rho_{a} C_{p}\left(T_{w}-T_{a}\right)=K_{h}\left(T_{w}-T_{a}\right) \quad\left(\mathrm{W} \mathrm{m}^{-2}\right)
$$

where $\rho_{a} C_{p}$ : specific heat capacity of the air $\left(\mathrm{J} \mathrm{m}^{-3} \mathrm{~K}^{-1}\right)$, $r_{a h}$ is the aerodynamic resistance for sensible heat transfer through the surface air layer, and $K_{h}$ is the sensible heat transfer coefficient $\left(\mathrm{W} \mathrm{m}^{-2} \mathrm{~K}^{-1}\right)$.

Latent heat flux from the water surface is expressed as:

$$
\begin{aligned}
\lambda E & =\frac{1}{r_{a v}} \lambda\left(\rho_{v}\left(T_{w}\right)-\rho_{v}\left(T_{a}\right)\right)=\frac{1}{r_{a v}} \frac{\rho_{a} C_{p}}{\gamma}\left(e_{s}\left(T_{w}\right)-e_{a}\right) \\
& =K_{v}\left(e_{s}\left(T_{w}\right)-e_{a}\right)\left(\mathrm{W} \mathrm{m}^{-2}\right)
\end{aligned}
$$

where $\rho_{v}\left(T_{w}\right), \rho_{v}\left(T_{a}\right)$ : water vapor densities at the water surface and in the surface air layer, respectively, $K_{v}$ : water vapor transfer coefficient $\left(\mathrm{W} \mathrm{m}^{-2} \mathrm{hPa}^{-1}\right)$. If we suppose the aerodynamic resistance for vapor transfer through the surface air layer, $r_{a v}$, is equal to $r_{a h}$, we get the following relation from Eqs.(11) and (12):

$$
K_{v}=\frac{1}{r} K_{h}
$$

Mihara et al. (1959b) empirically derived the relationship between the heat transfer coefficients, $K_{h}$ and $K_{v}$, and the wind speed at $2 \mathrm{~m}$ height, $U_{2}\left(\mathrm{~m} \mathrm{~s}^{-1}\right)$. They set $\Delta t$ to be one hour $(3,600 \mathrm{~s})$ and the number of measurements during $\Delta t, n$, to be one; that is, they obtained $K_{h}$ and $K_{v}$ every hour, when they used the 2-min mean of the wind speed.

Since $K_{h}=\frac{1}{r_{a v}} \rho_{a} C_{p}$, this coefficient depends on the air pressure. Further, because $\gamma$ is proportional to the air pressure $\left(=0.000646 P \mathrm{hPa} \mathrm{K}^{-1}\right)$, the relation of $K_{v}$ to the air pressure is more complicated. So, strictly speaking,

Table 1. Description of a part of the instruments installed at the AWS

\begin{tabular}{cccc}
\hline Variables & Instruments & Observation Frequency (miu.) & Height \& Depth (m) \\
\hline Air Temperature \& Humidity & HMP45AC (VAISALA) & 10 & 5 \\
Wind Speed & 010C-1 (MET ONE) & 10 & 10 \\
Atmosphere Pressure & CS100 (VAISALA) & 10 & 1.2 \\
Water Temperature \& Speed & Flowatch (NTECH) & - & -0.15 \\
\hline
\end{tabular}


their empirically derived relationships are applicable only to the area where the air pressure is almost the same as their observation site (about $200 \mathrm{~m}$ a.s.l.) (Mihara et al., 1959b).

The altitude of the present study area is about $1,500 \mathrm{~m}$ a.s.l., and hence the air pressure is, on average, about $85 \%$ of that at their observation site. However, as a first approximation, we assumed $K_{h}$ to be applicable to our study area and $K_{v}$ was obtained from the relationship between them as shown in Eq.(13); that is,

$$
\begin{aligned}
& K_{h}=4.0+3.1 U_{2} \\
& K_{v}=\frac{1}{0.000646 P}\left(4.0+3.1 U_{2}\right)
\end{aligned}
$$

where $P$ : air pressure $(\mathrm{hPa})$.

This relationship was derived using the data obtained in the daytime when the vertical profile of air temperature was super-adiabatic, that is, the vertical air temperature gradient was larger than the dry-adiabatic lapse rate $\left(0.0098 \mathrm{~K} \mathrm{~m}^{-1}\right)$. Hence, $H$ and $\lambda E$ should be overestimated at night if Eq.(14) is used.

Thus, the rate of evaporation from the irrigation canal is given by

$$
E_{i c}=\frac{1}{\lambda \rho_{w}} \frac{1}{0.000646 P}\left(4.0+3.1 U_{2}\right)\left(\begin{array}{c}
\left(e_{s}\left(T_{w, i}\right)-e_{a}\right) \\
\left(\mathrm{m} \mathrm{s}^{-1}\right)
\end{array}\right.
$$

where $T_{w, i c}$ : water temperature in the irrigation canal, $\lambda$ : heat of water vaporization at the temperature $T_{w, i c}$ $\left(\approx 2.5 \times 10^{6} \mathrm{~J} \mathrm{~kg}^{-1}\right), \rho_{w}$ : density of liquid water $\left(\mathrm{kg} \mathrm{m}^{-3}\right)$.

The amount of irrigation water lost in transport due to evaporation, $L_{e v}$, and the loss ratio due to evaporation of irrigation water, $L R_{e v}$, are defined as:

$$
\begin{aligned}
& L_{e v}=\int_{0}^{t_{t}} E_{i c} d t \\
& L R_{e v}=\frac{L_{e v}}{\mu D_{w}}
\end{aligned}
$$

where $t_{t}$ : time for water transport (=canal length $/ V$ )(s), $\mu$ : cross-section shape factor $(-) \mu=1 / 2$, if triangle; $\mu=1$, if rectangle).

\section{RESULTS AND DISCUSSION}

Table 2 shows the weather conditions and the daily mean flow speed in the canal during the periods of preliminary observation. Observations of meteorological elements are the averages of the two AWSs. Water flow speed and temperature were measured a few times a day at the two depths, $0.3 D_{w}$ and $0.6 D_{w}$, where $D_{w}$ is the water depth in the canal, which averaged about $40 \mathrm{~cm}$ (Fig. 3). However, because the diurnal changes in the temperature and flow speed and the differences between the measurements made at the two depths were small, the daily mean of the measurements made at $0.3 D_{w}$ was used in this study.

Using the meteorological observations taken at an interval of 10 minutes and the daily mean water temperature, we calculated $E_{i c}$ from Eq.(16). Fig. 4 illustrates the diurnal changes of $E_{i c}$ in three days of June. The values on the ordinate are given in units of $10^{-5} \mathrm{~mm} \mathrm{~s}^{-1}$, which is equivalent to $0.86 \mathrm{~mm} \mathrm{~d}^{-1}$. The diurnal changes on 22 and 24 June were similar to each other. The magnitude of the cumulative evaporation depth in the daytime (8:0020:00) was about twice as large as that in the nighttime (20:00-8:00) on both days, while on 23 June the cumulative depths by day and at night were almost the same as shown in Fig.6.

Figure 5 shows the diurnal changes in air temperature and relative humidity on 22 and 23 June. During two periods between $21: 00$ and 24:00 of 22 June and 5:00 and 7:00 of 23 June, when the evaporation rate was rather large, relative humidity was low, although air tempera-

\begin{tabular}{|c|c|c|c|c|c|c|}
\hline Date & $\begin{array}{l}\text { Air temper.* } \\
\text { at } 2 \mathrm{~m}\left({ }^{\circ} \mathrm{C}\right)\end{array}$ & $\begin{array}{l}\text { Air humid.* } \\
\text { at } 2 \mathrm{~m}(\%)\end{array}$ & $\begin{array}{l}\text { Wind speed* } \\
\text { at } 2 \mathrm{~m}\left(\mathrm{~m} \mathrm{~s}^{-1}\right)\end{array}$ & $\begin{array}{l}\text { Solar radiation } \\
\quad\left(\mathrm{MJ} \mathrm{m}^{-2} \mathrm{~d}^{-1}\right)\end{array}$ & $\begin{array}{l}\text { Rainfall } \\
\left(\mathrm{mm} \mathrm{d}^{-1}\right)\end{array}$ & $\begin{array}{c}\text { Flow speed } * \\
\qquad\left(\mathrm{~m} \mathrm{~s}^{-1}\right)\end{array}$ \\
\hline 22 June & 23.5 & 36.6 & 1.81 & 23.1 & - & 2.8 \\
\hline 23 June & 20.1 & 51.8 & 1.81 & 16.2 & - & 2.8 \\
\hline 24 June & 21.1 & 41.4 & 1.14 & 30.1 & - & 2.6 \\
\hline 21 July & 20.8 & 69.9 & 0.95 & 25.8 & 2.5 & 2.5 \\
\hline 22 July & 20.4 & 60.5 & 1.37 & 15.3 & - & 2.5 \\
\hline 23 July & 19.8 & 58.6 & 1.62 & 18.7 & - & 2.5 \\
\hline 24 July & 18.8 & 70.4 & 1.01 & 16.9 & - & 2.5 \\
\hline 13 August & 19.8 & 77.3 & 1.08 & 14.4 & 1.5 & 2.6 \\
\hline 14 August & 20.9 & 68.3 & 0.89 & 26.2 & 0.1 & 2.6 \\
\hline 15 August & 22.4 & 49.4 & 1.29 & 23.9 & - & 2.5 \\
\hline
\end{tabular}
ture and wind speed remained nearly constant. In the daytime of 23 June, relative humidity was, as would be expected, higher than that of 22 June, and the evapora-

Table 2. Weather conditions and the daily mean flow speed in the canal during the periods of preliminary observation

\footnotetext{
* Daily mean.
} 


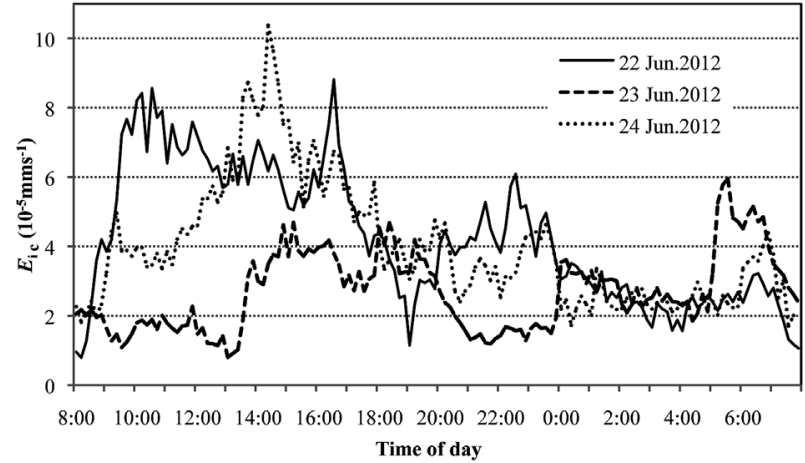

Fig. 4. Diurnal changes of $E_{i c}$ in three days of June.

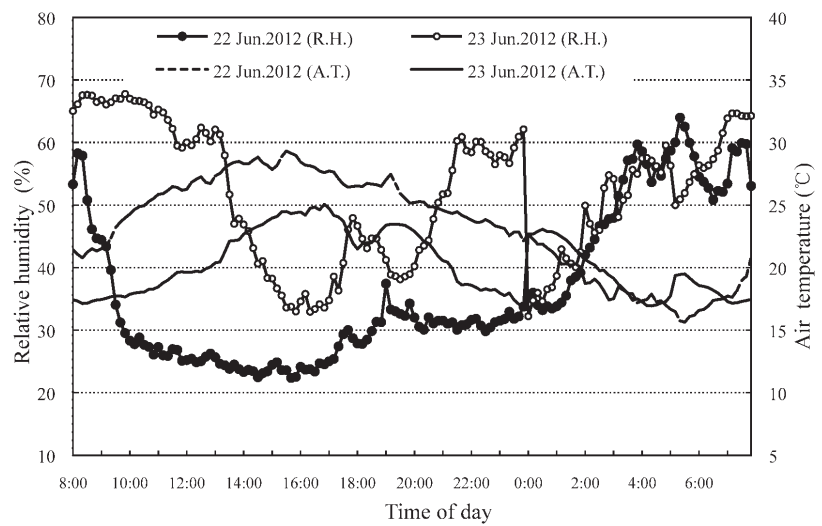

Fig. 5. Diurnal changes in air temperature and relative humidity on 22 and 23 June.

tion rate during the day of 23 was much smaller than that of 22 June. These results suggest that the evaporation from the irrigation canal is very sensitive to the air humidity.

Figure 6 shows the day-to-day changes of the daytime (white), nighttime (black), and daily cumulative evaporation depth (gray). Contrary to expectation, the maximum of daily evaporation depth from irrigation canals occurred in June, and daily evaporation was often almost zero or negative in July and August.

Figure 7 shows the seasonal changes in the daily mean air temperature, relative humidity, and the water temperature in the canal. Although the water temperature showed a slight increase during the summer months, it does not seem to exert its influence on the evaporation rate. Neither daily mean air temperature nor wind speed showed large seasonal changes during this period of time, but relative humidity was lower in the middle of and late in June, and late in August, than the other times. As for the diurnal variation of the rate of evaporation from irrigation canals, also for the seasonal variation, air humidity seems to have been the most important factor that controlled the evaporation rate.

Although, at first glance, the condensation of water vapor on the water surface may be strange, whether evaporation occurs or condensation occurs depends on the numbers of water molecules emitted from and received by the water surface. Thus, it is not strange that conden-

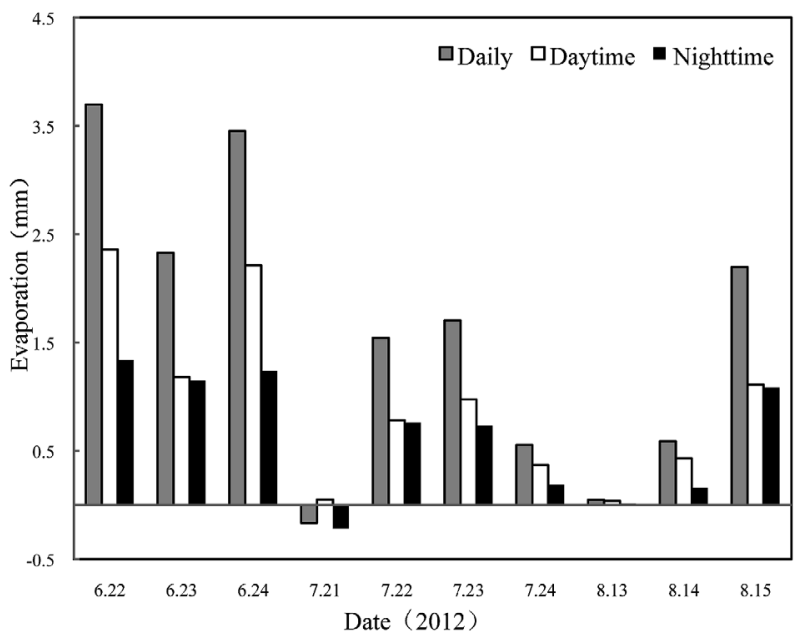

Fig. 6. Day-to-day changes of the daytime (white), nighttime (black), and daily cumulative evaporation depth (gray).

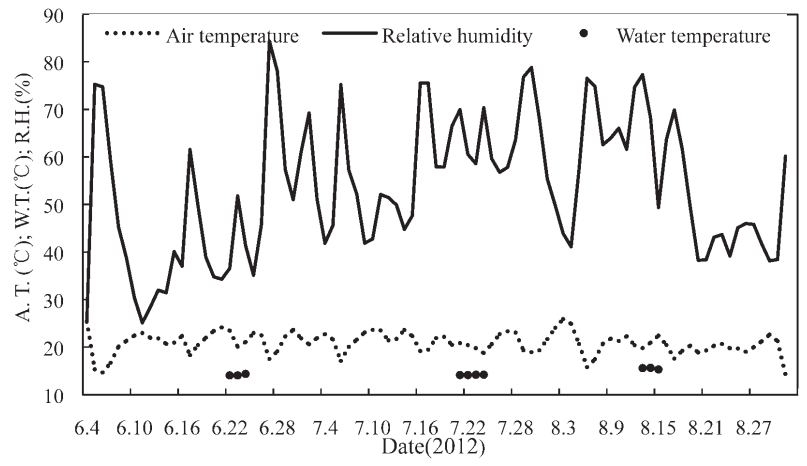

Fig. 7. Seasonal changes in the daily mean air temperature, relative humidity, and the water temperature in the canal.

sation occurs when the water temperature is low enough relative to the air humidity.

Lastly, let us estimate $L_{e v}$ and $L R_{e v}$ defined by Eqs. (17) and (18). If $D_{w}=40 \mathrm{~cm}, \mu=1 / 2, t_{t}=$ one day, and $E_{i c}$ obtained on 22 June 2012 is used, $L_{e v}=3.7 \mathrm{~mm}$ and $L R_{e v}=0.02$. As mentioned above, the results obtained in this study are only approximate, but the loss of irrigation water due to evaporation seems to be an order of magnitude smaller than the water loss due to the leakage into the ground from the whole canal network, because Fipps (2000, as cited by Huang et al., 2010) estimated that the Rio Grande region (region M) had an average conveyance efficiency of $70 \%$ or $30 \%$ of the amount of irrigation water was lost due to the leakage.

\section{CONCLUDING REMARKS}

The rate of evaporation from irrigation canals depends on $\Delta T=T_{w}-T_{a}$, air humidity, and $U_{2}$. In the period of the present preliminary observation, the variations of $\Delta T$ and $U_{2}$ with time were not so large, and hence air humidity had a large influence on the evaporation rate. Since the Heihe River rises from the Qilianshan Mountains and the river water is melt-water, $T_{w}$ is rather low compared to the air temperature. As a result, daily 
evaporation depth was often almost zero or negative. Although $K_{h}$ is related to the air pressure, Eq.(14) obtained in lowland areas (about $200 \mathrm{~m}$ a.s.l.) in Japan was, as a first approximation, used to the present case in this highland area (about 1,500 m a.s.l.) in the north west of China. Since $K_{v}$ depends on the air pressure in a complicated manner, the approximate relation as shown in Eq.(13) was used and the empirical relation given by Mihara et al. (1959b) was not applied to this case. However, these estimates are only approximate and should be verified against observational evidence before a final conclusion can be drawn. We are planning to do such an experiment in the next irrigation season. However, it seems reasonable to say that the loss of irrigation water due to evaporation should be an order of magnitude smaller than the water loss due to the leakage into the ground from the whole canal network.

\section{ACKNOWLEDGRMENTS}

We wish to thank Mr. S. Matsuda of the Agricultural Research Center, Zentsuji, Japan, and Prof. X. Li of CAREEI, CAS, China, for their assistance in surveying literature. We also thank J. Zhuang, F. Xu, C. Ma and Y. Ge of Cold and Arid Regions Environmental and
Engineering Institute, CAS for their help in conducting field observations. This work is supported by The CAS Action-plan for West Development (grant number: KZCX2-XB3-15); and the National Natural Science Foundation of China (grant number: 9125002 and 41271359).

\section{REFERENCES}

Huang, Y., G. Fipps, S. J. Maas and R. S. Fletcher 2010 Airbone remote sensing for detection of irrigation canal leakage. Irrig. and Drain., 59: 524-534

Kobayashi, T. 2012 Physics of Agricultural Environment. Cold and Arid Regions Environmental and Engineering Institute, CAS.

Li, X., Liu, S., Ma, M., Xiao, Q., Liu, Q., Jin, R., Che, T., Wang, W., Qi, Y., Li, H., Zhu, G., Guo, J., Ran, Y., Wen, J., Wang, S., 2012 HiWATER: An integrated remote sensing experiment on hydrological and ecological processes in the Heihe River Basin. Advances in Earth Science, 2012, 27(5): 481-498 (in Chinese)

Mihara, Y., Z. Uchijima, S. Nakamura and K. Onuma 1959a A study on heat balance and water temperature rising of the warming pond. Bulletin Nation. Inst. Agric. Sci., Japan, A-7: 1-44. (in Japanese with English summary)

Mihara, Y., Z. Uchijima and S. Nakamura 1959b A study on heat balabce of the water warming channels. Bulletin Nation. Inst. Agric. Sci., Japan, A-7: 45-68 (in Japanese with English summary) 